\title{
A CENTRALIDADE DO COMPLEXO-SOJA NA ECONOMIA BRASILEIRA E A MANUTENÇÃO DA PRODUÇÃO AGRÍCOLA EXTRAVERTIDA: ANÁLISE DA SOJA EM MATO GROSSO DO SUL
}

Ana Carolina Torelli M. Faccin ${ }^{1}$ Ricardo Castillo²

Resumo: O objetivo central desse artigo é discutir a dinâmica da produção de soja em Mato Grosso do Sul (Brasil), que reproduz a dinâmica atual da economia nacional, pautada em produtos primários de grande expressão e importância econômica no mercado mundial, compreendendo que tal fato gera grande impacto no espaço produtivo dos países periféricos, ocasionando extrema especialização produtiva. Tal fenômeno, profundamente ligado à demanda internacional por commodities, foi acentuado, em particular, pela entrada da China na Organização Mundial do Comércio (OMC) em 2001 e pelos atrativos preços pagos pela soja e outros produtos de circulação mundial neste período. Usando como metodologia a análise de dados de produção e balança comercial sob uma abordagem teórica com revisão de autores ligados à Geografia econômica brasileira, concluímos que tal movimento global influencia diretamente a organização do espaço dos países de economia periférica como o Brasil, instalando lógicas globais de produção e dinâmicas voltadas à exportação, com poucas relações e obrigações com o lugar.

Palavras-chave: Brasil. Soja. Especialização produtiva. Mato Grosso do Sul. Organização do espaço.

\section{THE CENTRALITY OF SOYBEAN COMPLEX IN THE BRAZILIAN ECONOMY AND THE MAINTENANCE OF EXTRAVERTED AGRICULTURAL PRODUCTION: ANALYSIS OF SOYBEAN CULTIVATION IN MATO GROSSO DO SUL (BRAZIL)}

\begin{abstract}
The main objective of this article is to discuss the dynamics of soybean production in Mato Grosso do Sul (Brazil), which reproduces the current dynamics of the national economy, based on primary products of great expression and economic importance in the world market, understanding that this fact generates great impact in space production of peripheral countries, causing extreme specialization in production. This phenomenon, deeply linked to international demand for commodities, was particularly marked by China's entry into the World Trade Organization (WTO) in 2001 and the attractive prices paid for soybeans and other products of global circulation in this period. Using as methodology the analysis of production data and trade balance under a theoretical approach with review of authors related to brazilian economic Geography, we conclude that such a global movement directly influences the organization of the space of peripheral economies like Brazil, installing global logics of production and export-oriented dynamics, with few relationships and obligations with the place.
\end{abstract}

Keywords: Brazil. Mato Grosso do Sul. Soybean. Productive specialization. Space organization.

\footnotetext{
${ }^{1}$ Universidade Federal da Grande Dourados, Faculdade de Ciências Humanas, Dourados, Brasil, caroltorelli.faccin@gmail.com, http://orcid.org/0000-0001-8740-4689

2 Universidade Estadual de Campinas, Departamento de Geografia, Campinas, Brasil, castillo@unicamp.br, https://orcid.org/0000-0002-7056-3197
} 


\section{LA CENTRALIDAD DEL COMPLEJO-SOJA EN LA ECONOMÍA BRASILEÑA Y EL MANTENIMIENTO DE LA PRODUCCIÓN AGRÍCOLA EXTRAVERTIDA: ANÁLISIS DE LA SOJA EN MATO GROSSO DEL SUR (BRASIL)}

Resumen: El objetivo central de este artículo es discutir la dinámica de la producción de soja en Mato Grosso do Sul (Brasil), que reproduce la dinámica actual de la economía nacional, pautada en productos primarios de gran expresión e importancia económica en el mercado mundial, comprendiendo que tal hecho genera un gran impacto en el mercado espacio productivo de los países periféricos, ocasionando extrema especialización productiva. Este fenómeno, profundamente ligado a la demanda internacional por commodities, fue acentuado, en particular, por la entrada de China en la Organización Mundial del Comercio (OMC) en 2001 y por los atractivos precios pagados por la soja y otros productos de circulación mundial en este período. En cuanto a la metodología del análisis de datos de producción y balanza comercial bajo un enfoque teórico con revisión de autores ligados a la Geografía económica brasileña, concluimos que tal movimiento global influye directamente en la organización del espacio de los países de economía periférica como Brasil, instalando lógicas globales producción y dinámicas orientadas a la exportación, con pocas relaciones y obligaciones con el lugar.

Palabras clave: Brasil. Mato Grosso do Sul. Soja. Especialización productiva. Organización del espacio.

\section{Introdução}

Nas últimas décadas a agricultura brasileira vem passando por um gradual e seletivo processo de modernização, com a introdução maciça de transformações na base técnica e na base organizacional da atividade (DELGADO, 1985) e da fração do território que lhe corresponde (CASTILLO, 2015), sendo que todo esse processo também vem acompanhado por uma reestruturação profunda das relações sociais de produção no campo e na cidade.

Paralelamente a esse fato, no País a fronteira agrícola moderna se expandiu para o Cerrado (AB'SABER, 1977; DINIZ, 2006), tomando grandes porções da macrorregião Centro-Oeste de forma acelerada, contraditória e conflituosa. Por um lado, essa porção do território brasileiro mostrou-se muito receptiva aos processos de modernização produtiva da agricultura, dadas as suas características naturais (topografia e clima, principalmente) e sociais (estrutura fundiária concentrada, pouca capacidade de resistência das populações locais, migrantes empreendedores do Sul e do Sudeste com larga experiência no setor, preço da terra dentre outros). Por outro lado, a ausência de um sistema eficiente de transportes, armazenamento e comercialização e a distância em relação aos centros dinâmicos de consumo do mercado interno e aos portos exportadores criaram dificuldades para a sustentação do novo modelo produtivo. 
Por fim, o avanço dos investimentos públicos e privados na agricultura intensiva não ocorreu sem provocar conflitos com populações tradicionais, caracterizando aquilo que Harvey (2004) chamou de acumulação por espoliação e despossessão.

Nesse movimento geral de expansão da fronteira agrícola moderna no Cerrado, o estado de Mato Grosso do Sul, muito próximo do estado de São Paulo, tornou-se, inicialmente, uma "projeção da pecuária do sudoeste paulista", consolidando-se como um "complexo de carnes de importância nacional e contribuindo para que se firmassem os dois principais núcleos econômicos do estado: os municípios de Dourados e Campo Grande" (GUIMARÃES \& LEME, 2002, p. 28).

Em meados da década de 1960, chegaram ao estado os sulistas pioneiros da soja que, em razão da adaptação do grão às condições edafoclimáticas do Cerrado, iniciaram o seu cultivo em larga escala já na década de 1970, favorecidos por programas e incentivos públicos, o que desencadeou a agroindustrialização do então antigo Sul de Mato Grosso. Esta agroindústria, inicialmente, contava com baixo nível técnico e operava sob a tutela de pequenos grupos empresariais locais e regionais. Posteriormente, grandes empresas do agronegócio investiram na implantação de uma rede estratégica de armazenamento, acompanhando e estimulando o avanço da agricultura comercial no estado, para que esta servisse cada vez mais à exportação de commodities.

As ações combinadas entre Estado e empresas transformaram a realidade produtiva da região nas últimas décadas, propiciando, primeiramente, o fortalecimento do comércio inter-regional, para depois alcançar os mercados internacionais, com a implantação de grandes empresas do agronegócio no território sul-mato-grossense.

Desse modo, dois conceitos geográficos tornam-se fundamentais para analisar e interpretar essa situação. O primeiro deles é a região, conceito clássico da Geografia que assume novos contornos e novos conteúdos no decorrer das transformações históricas. A exacerbação da especialização regional produtiva caracteriza um tipo de região adaptada aos mercados internacionais, com relações que extrapolam o lugar e o território nacional, a chamada região produtiva (SANTOS, 1994), que se sobrepõe, se articula e estabelece relações de complementaridade e contradição com outras formas regionais (regiões naturais, regiões tradicionais e regiões de planejamento) (CASTILLO, 2015). 
A especialização regional produtiva, expressão do aprofundamento da divisão territorial do trabalho, guarda relação direta com o desenvolvimento dos transportes e comunicações, o que leva à consideração do conceito de redes geográficas (DIAS, 1995; DIAS, 2005; CORRÊA, 2012). A maior fluidez territorial propiciada pelas redes técnicas autoriza, mas não causa, a especialização regional produtiva (SANTOS, 1989), através do encurtamento das distâncias medidas em tempo e em custo, permitindo a dissociação entre o lugar da produção e o lugar do consumo.

Assim, formam-se regiões cujo maior atributo é a especialização produtiva, requisito fundamental para uma maior competitividade, não somente dos produtos e dos agentes econômicos, como também das frações do espaço que lhes dão suporte material e normativo.

Diante dessas considerações iniciais, neste artigo temos como objetivo discutir a dinâmica da produção de soja em Mato Grosso do Sul, estado da região Centro-Oeste, fronteiriço com os estados de São Paulo, Minas Gerais, Paraná, Goiás, Mato Grosso e também com Bolívia e Paraguai, apresentando as características intrínsecas da soja e analisando o uso do território que ocasiona uma extrema especialização produtiva extravertida, isto é, voltada para exportação. Com uma metodologia baseada em análise de dados, especialmente de exportação de produtos, balança comercial e compreensão da relação entre aumento da área plantada de soja e rendimento por hectare, discutimos, na segunda parte de nossa análise, o inevitável aprofundamento da especialização regional produtiva sul-matogrossense, fenômeno regional que exemplifica a situação atual do espaço agrícola brasileiro como um todo.

\section{Características intrínsecas da soja e uso do território}

Parte majoritária das mudanças atuais pelas quais passa a agricultura e o uso do território nos países periféricos é moldada por demandas globais por recursos naturais e commodities agrícolas, em uma conjunção de interesses que envolvem grandes corporações em busca de novas fronteiras de acumulação e Estados nacionais voltados a uma lógica corporativa do território. Assim, adotamos em nossa análise a seguinte definição:

Compreendemos commodity como um produto primário ou semielaborado, mineral ou agrícola, padronizado mundialmente, cujo preço é cotado nos mercados internacionais em bolsas de mercadorias. Trata-se de uma invenção não apenas econômico-financeira, mas também política, que enfraquece e submete o produtor local - pelo menos quando se trata de 
commodity agrícola - a uma lógica única ou global e a uma situação sobre a qual não exerce nenhum controle, favorecendo os compradores ou as grandes empresas de comercialização (tradings), à maneira como propõe Appudarai (1986). A lógica das commodities opõe agentes atrelados ao lugar ou região aos agentes que atuam em rede na escala mundial (CASTILLO, 2015, p. 6).

Nesse sentido, é bastante evidente nas últimas décadas o aumento da produção dos produtos denominados flex crops (culturas flexíveis), que apresentam múltiplos usos (alimentação humana, ração animal, combustível e usos industriais) (BORRAS JR et al, 2014). Atualmente, a soja talvez seja a matéria-prima que melhor representa essa categoria de produto agrícola, intimamente ligada à volatilidade dos preços no mercado mundial.

Salientar as características intrínsecas da soja é, portanto, essencial para compreender sua relação com o território. Além da flexibilidade acima mencionada, que permite mudar o destino da matéria-prima em razão das oscilações dos preços dos alimentos da cadeia grãos-carnes e dos preços do biocombustível, a soja é uma cultura anual de ciclo curto, o que the atribui outras vantagens, sobretudo em comparação com culturas permanentes. Duas dessas vantagens se destacam: a) a possibilidade de alternância de culturas num mesmo ano agrícola; b) a possibilidade de substituir a soja por outra cultura sem grandes prejuízos (CASTILLO, 2012). Todas essas qualidades da soja conspiram para uma acentuada especialização regional de sua produção e para a longevidade de sua prática, amenizando a vulnerabilidade econômica a que todas as regiões altamente especializadas estão sujeitas (CASTILLO, 2012).

O Brasil, atualmente apresentando alguns sintomas de desindustrialização (com moeda considerada valorizada demais/pouco competitiva em relação ao mercado internacional e com a indústria figurando no cálculo do produto interno bruto com cerca de 10\%) (WENTZEL, 2016), continua a manter sua pauta exportadora majoritariamente baseada em produtos básicos do setor primário, com pouco ou nenhum valor agregado (quadro 1). 
Quadro 1. Brasil. Visão geral dos produtos exportados: participação em relação ao valor exportado, 2018.

\section{Brasil}

Total: USS 54,67 Bilhões

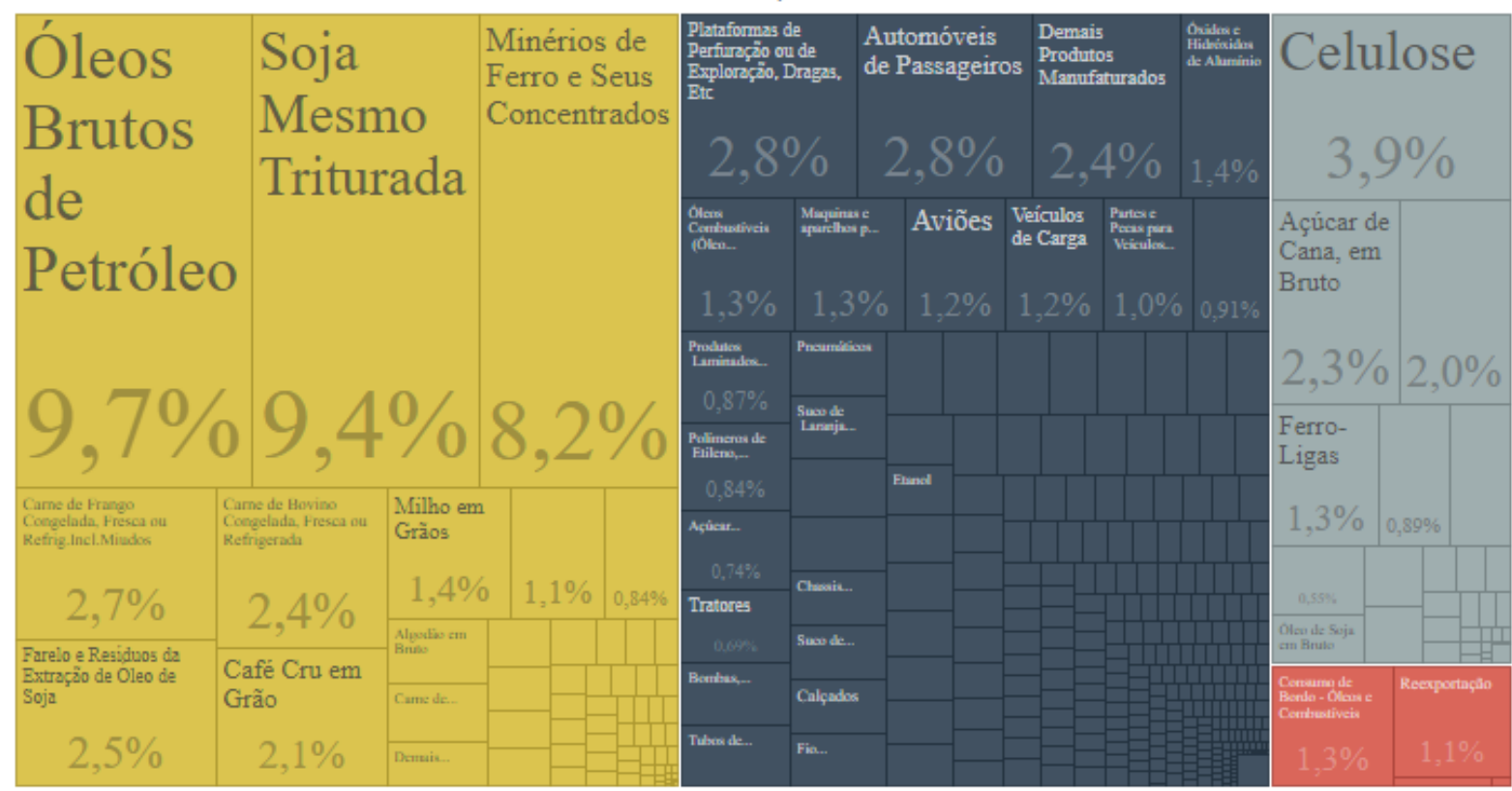

\section{문중}

Fonte: Reprodução Comex vis/MDIC (2019).

Podemos observar, com auxílio do quadro 1 , que alguns produtos do complexo soja, representados separadamente pelos termos "soja mesmo triturada" e "farelos e resíduos de extração de óleo de soja", representam o somatório de 11,9\% do total de valor de produtos exportados pelo Brasil em 2016, ocupando assim o primeiro lugar nesse ranking.

Em comparação, a matriz exportadora do estado de Mato Grosso do Sul (quadro 2) segue a mesma composição, resguardadas as devidas proporções: os produtos do complexo-soja ocupam a primeira posição entre os produtos exportados (a soma equivale a $37,4 \%$ ), seguido de perto pela parte que cabe à celulose $(33 \%)$, açúcar bruto de cana $(3,1 \%)$, carne de boi congelada $(9,7 \%)$, carne de frango congelada $(4,8 \%)$, minérios de ferro $(2,05 \%)$ e milho em grãos $(1,5 \%)$. 
Quadro 2. Mato Grosso do Sul. Visão geral dos produtos exportados, 2018

Mato Grosso do Sul

Total: USS 5,69 Bilhões

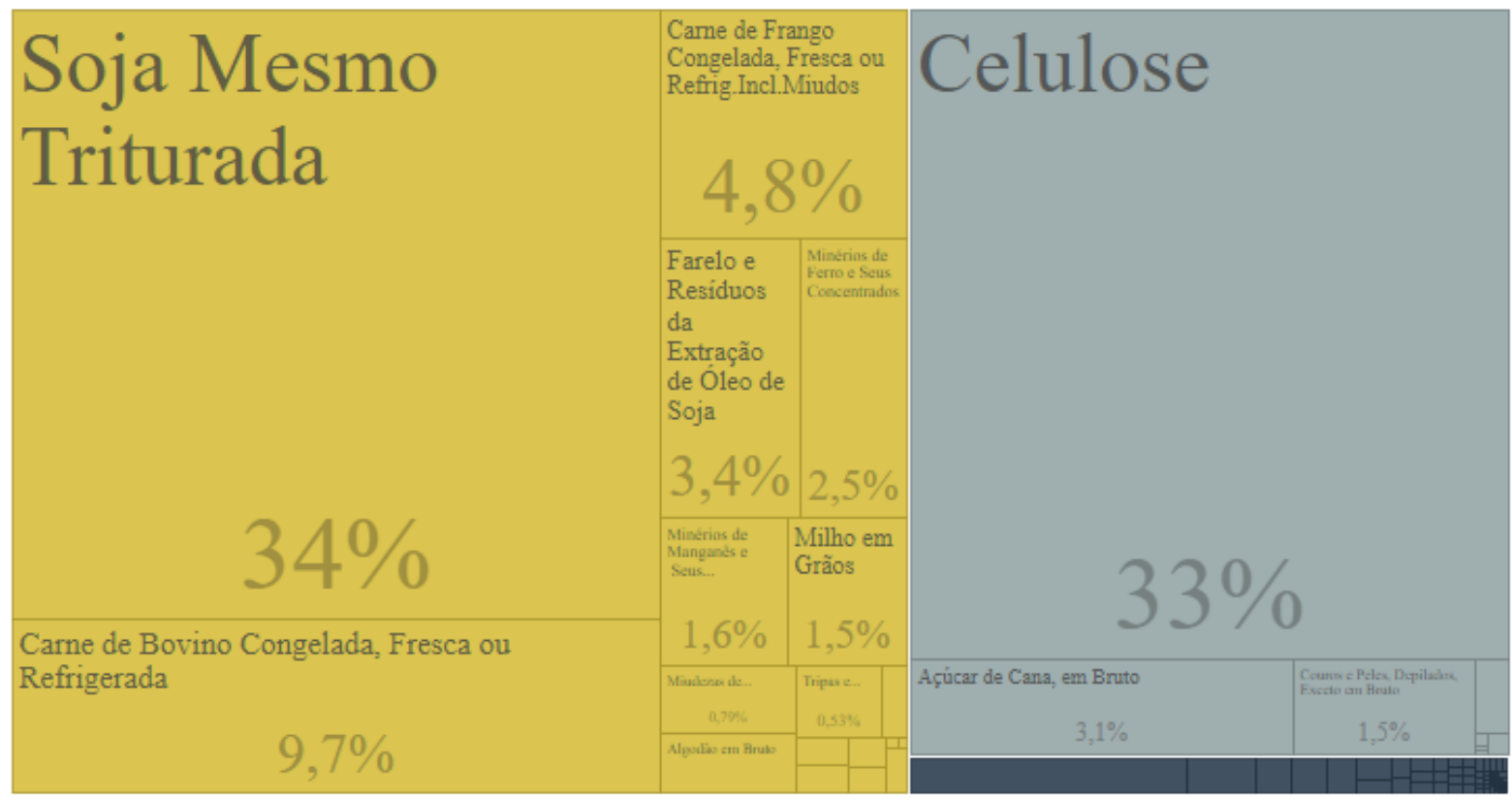

뭉

Fonte: Reprodução Comex vis/MDIC (2019).

A matriz produtiva de Mato Grosso do Sul é, de certa maneira, uma reprodução mais simplificada da visão geral dos produtos exportados pelo País e sugere um fato marcante: a soja, a pecuária, a cana-de-açúcar e a silvicultura são as atividades mestras da economia sul-mato-grossense, sendo que qualquer atividade de destaque (por exemplo, setor de indústria e, parcialmente, o de serviços) se desdobra dos produtos primários, ou seja, existe em função da manutenção dos circuitos espaciais criados para a efetivação dessas poucas atividades principais. Os efeitos práticos dessa pauta exportadora na organização do espaço são claros: no território sul-mato-grossense as lavouras têm protagonismo inegável (mapa 1), principalmente de soja (cujas áreas rotacionam com o cultivo de milho, por motivos fitossanitários), cana-de-açúcar e eucalipto (silvicultura) e tais formas de produção dividem espaço com atividade mineradora (porção pantaneira noroeste do estado) e com a pecuária, tradicional em todo o estado. 
Mapa 1. Mato Grosso do Sul. Localização georreferenciada das lavouras de algodão, cana-de-açúcar, eucalipto, soja/milho, pasto, remanescentes e outros usos, 2016.

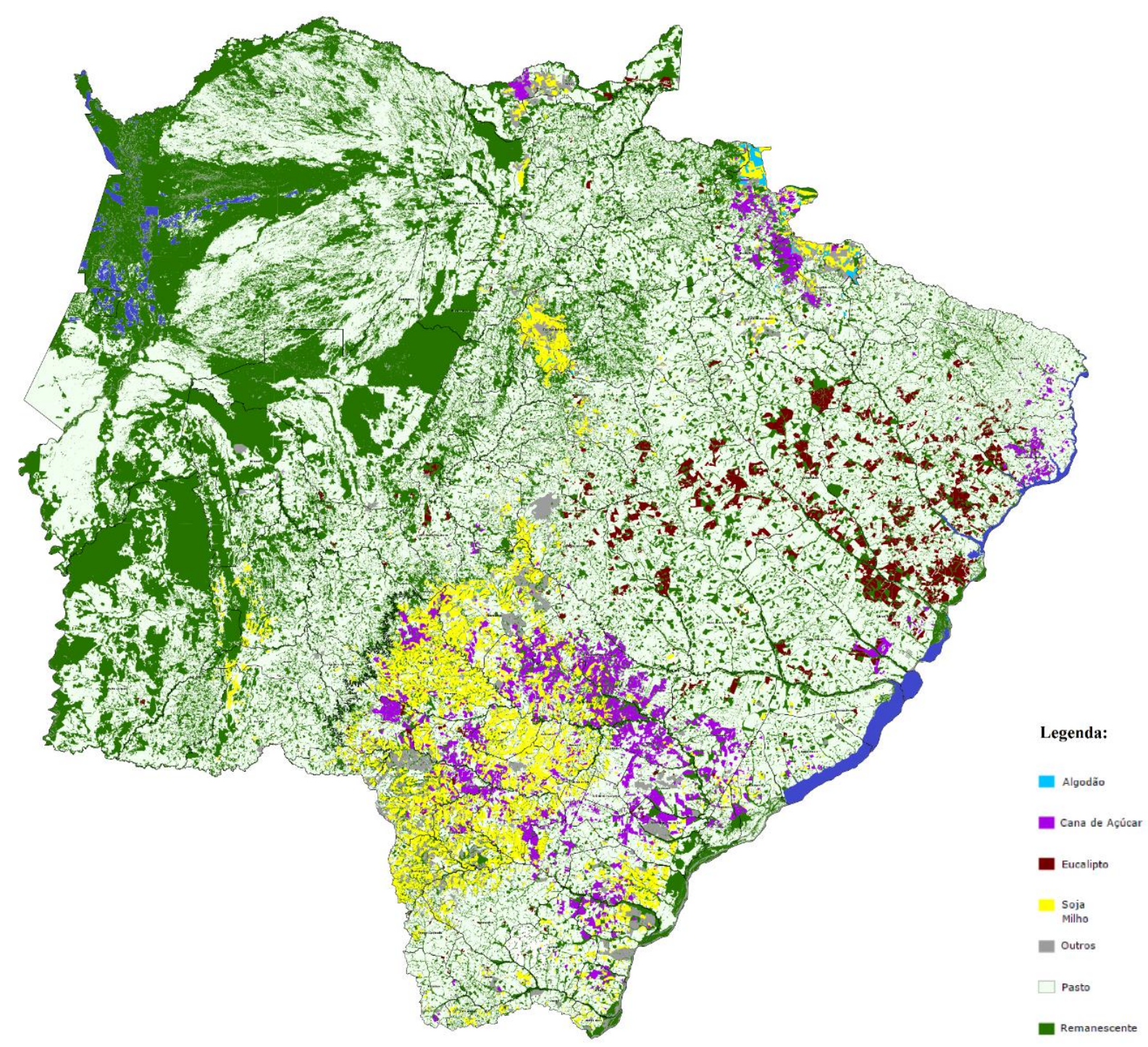

Fonte: SIGAWEB/MS (2016). Organizado por FACCIN (2017).

Dentre essas poucas atividades que regem a economia do estado, é inegável a importância do complexo soja, a exemplo do que ocorre também em escala nacional. Uma estimativa realizada pela EMBRAPA para o ano de 2015 evidencia a importância do complexo-soja para o saldo positivo da balança comercial do Brasil (gráfico 1). 


\section{Gráfico 1. Estimativa da contribuição do complexo-soja no saldo da balança comercial brasileira.}
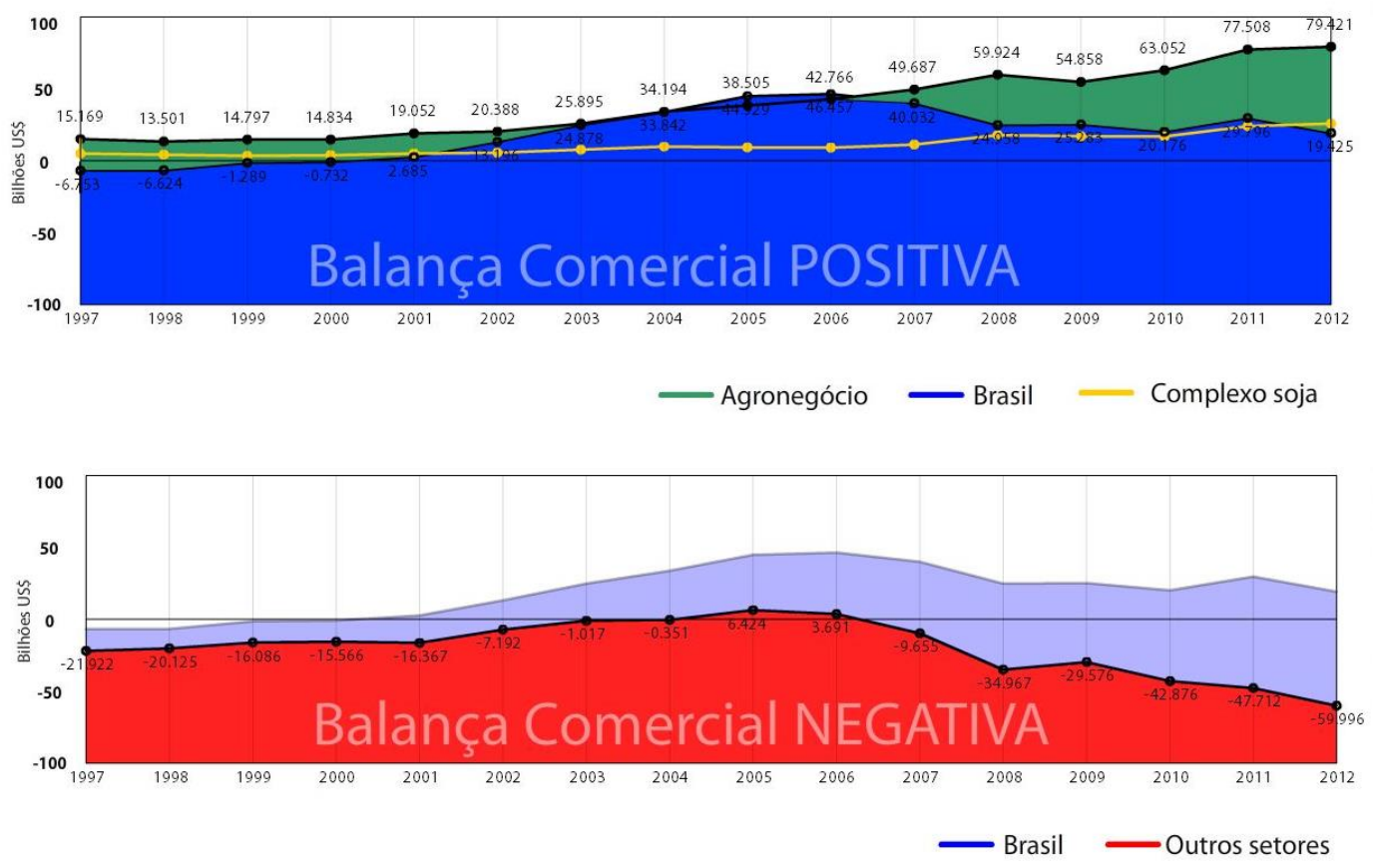

Fonte: EMBRAPA (2015).

Historicamente, o setor agropecuário brasileiro nunca deixou de cumprir com suas funções na economia, tanto para o mercado interno, incluindo o fornecimento de matérias-primas às indústrias e o barateamento da reprodução da força de trabalho urbana, quanto para os mercados internacionais (CASTRO, 1969). Particularmente, a partir da década de 2000 , os números da balança comercial brasileira revelam a dependência do país em relação ao setor agropecuário em sua pauta de exportação, ainda que, em números absolutos, a exportação de produtos industriais não tenha diminuído (GONÇALVES, 2011; LAMOSO, 2011), apesar de alguns autores discordarem dessa interpretação (CANO, 2012).

Nesse contexto, muito do atual destaque do complexo soja se deve às facilidades concedidas pelo governo brasileiro no que se refere ao recolhimento de impostos sobre mercadorias (ICMS). Leis, como a Lei Kandir, de 1996, levaram ao favorecimento da exportação de diversos produtos in natura; a exportação do grão de soja cresceu exponencialmente após a determinação da lei (gráfico 2), enquanto o óleo e o farelo, com mais valor agregado, tiveram uma queda expressiva no mesmo período. 


\section{Gráfico 2. Brasil. Mix de exportações do complexo soja, antes e depois da Lei}

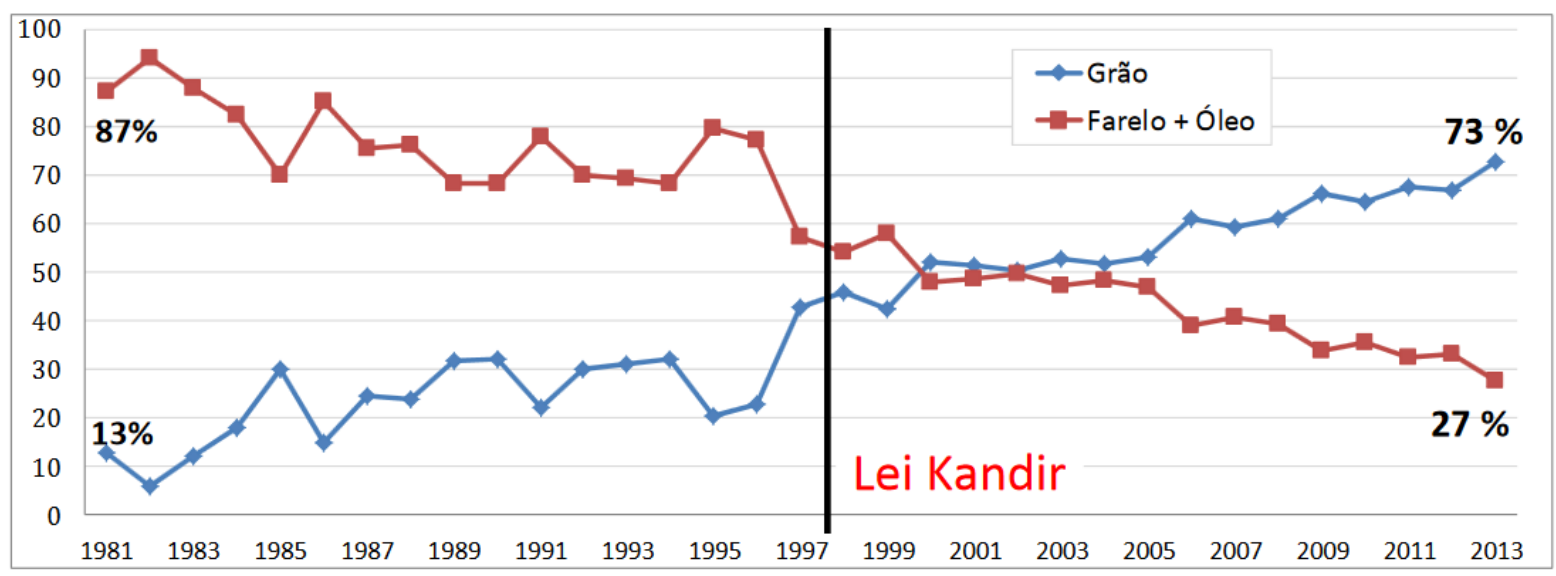

Kandir, 1981-2013.

Fonte: ABIOVE (2013).

Uma medida governamental que incentiva a exportação de produtos de baixo ou nenhum valor agregado gera implicações profundas no território. A lei Kandir isenta do tributo ICMS os produtos e serviços destinados à exportação. Considerando o ICMS, na Lei Complementar o 87 (1996). Art. 3o O imposto não incide sobre: "II - Operações e prestações que destinem ao exterior mercadorias, inclusive produtos primários e produtos industrializados semielaborados, ou serviços; Parágrafo único: Equipara-se às operações de que trata o inciso II a saída de mercadoria realizada com o fim específico de exportação para o exterior, destinada a: I - Empresa comercial exportadora, inclusive tradings ou outro estabelecimento da mesma empresa; II - Armazém alfandegado ou entreposto aduaneiro". Juntamente com a isenção de tarifas de exportação, há uma diminuição dos incentivos para se consolidar uma agroindústria de beneficiamento e processamento nas localidades onde a soja é produzida.

Há diversos efeitos relacionados a essa escolha fiscal por parte do governo, entre eles indícios de desindustrialização da economia e perda de complexidade econômica da pauta exportadora, sendo que alguns economistas até mesmo indicam a existência de efeitos da famigerada "doença holandesa" no Brasil. A doença holandesa, em termos gerais, caracteriza a insistência de um país em explorar seus recursos naturais/produtos de baixo valor agregado e, em razão dessa situação, ter seu setor manufatureiro/alto valor agregado em declínio.

É fato amplamente demonstrado que o desenvolvimento do capitalismo do Brasil tem decisiva intervenção do poder público, sobretudo nas últimas décadas, quando, através de múltiplos instrumentos, visando à valorização do capital e, quase sempre, penalizando o trabalho, vem produzindo 
transformações que afetaram a divisão regional do trabalho no País (SOUZA, 2008, p. 17).

A política fiscal adotada também é alvo de críticas do próprio setor produtivo da soja que, em seus estudos internos, compara a situação do Brasil com outros países, como a China, Argentina e EUA (quadro 3).

\section{Quadro 3. China, Argentina, Brasil e EUA. Comparação de políticas governamentais de incentivo à exportação de produtos do complexo-soja, 2013.}

\begin{tabular}{|c|c|c|c|}
\hline China & Argentina & Brasil & EUA \\
\hline$\frac{\text { Proteção ao mercado de }}{\text { produtos }}$ & $\frac{\text { Apoio à exportação de }}{\text { produtos }}$ & $\frac{\text { Incentivo à exportacão de }}{\underline{\text { matérias-primas }}}$ & $\frac{\text { Proteção ao mercado }}{\underline{\text { interno de produtos }}}$ \\
\hline $\begin{array}{l}\text { - Apoio governamental ao } \\
\text { investimento }\end{array}$ & $\begin{array}{l}\text { - Diferencial tributário de } \\
\text { exportação (DTE) }\end{array}$ & $\begin{array}{l}\text { - Falta de isonomia na } \\
\text { exportação - ICMS }\end{array}$ & $\begin{array}{c}\text { - Tarifa elevada no óleo de } \\
\text { soja }\end{array}$ \\
\hline $\begin{array}{c}\text { - Fornecimento de matéria- } \\
\text { prima pelo governo }\end{array}$ & $\begin{array}{l}\text { - Fornecimento de energia } \\
\text { subsidiada }\end{array}$ & $\begin{array}{l}\text { - Falta de isonomia na } \\
\text { exportação - FUNRURAL }\end{array}$ & \\
\hline - Escalada tarifária & & $\begin{array}{l}\text {-Acumulo forte de créditos } \\
\text { Falta de saídas tributadas }\end{array}$ & \\
\hline $\begin{array}{l}\text { - Barreira técnica ao óleo de } \\
\text { soja }\end{array}$ & & $\begin{array}{c}\text { Crédito Presumido - Falta } \\
\text { total de liquidez após Lei } \\
12.839\end{array}$ & \\
\hline $\begin{array}{l}\text { - Controle das licenças de } \\
\text { importação do farelo de soja }\end{array}$ & & $\begin{array}{l}\text { - Redução do crédito } \\
\text { presumido }\end{array}$ & \\
\hline
\end{tabular}

Fonte: ABIOVE (2013).

As demandas dos produtores de grãos, assim como de outros subsetores da agropecuária, se traduzem na enorme força da bancada ruralista brasileira no Congresso Nacional, sempre envolvida em cargos de grande poder político, com grande poder de barganha em relação aos cargos legislativos e executivos e com forte influência em votações de pautas de relevante interesse social. Tal bancada se mostra particularmente dedicada a barrar, há décadas, projetos que poderiam viabilizar ações urgentes para o País, como a reforma agrária e demarcação de terras indígenas.

\section{O aprofundamento da especialização regional produtiva extravertida}

A especialização regional produtiva, expressão do aprofundamento da divisão territorial do trabalho, guarda relação direta com o desenvolvimento dos transportes e comunicações. A maior fluidez territorial propiciada pelas redes técnicas autoriza, mas não causa, a especialização regional produtiva (SANTOS, 1989), através do 
encurtamento das distâncias medidas em tempo e em custo, permitindo a dissociação entre o lugar da produção e o lugar do consumo.

A especialização regional produtiva, isto é, a reunião de fatores produtivos e de condições particulares (serviços, armazenamento, terminais, comércio, centros de pesquisa e informação) numa determinada porção do território gera condições para o aumento da produção e da produtividade, elevando, portanto, a competitividade de alguns lugares e regiões para um determinado tipo de produção (CASTILLO, 2007, p. 37).

Para atestar de maneira concreta a evolução a expansão da cultura da soja em Mato Grosso do Sul voltamos nossa atenção à análise dos dados da evolução da área plantada e evolução do rendimento médio das lavouras de soja, de 1990 a 2017 (gráfico 3) e à espacialização dos dados da evolução da área plantada de soja, de 1990 a 2015, em intervalos de 5 anos (mapa 2).

O gráfico mostra que ocorreu uma inversão a partir de 2004, ou seja, houve um protagonismo temporário do crescimento da área plantada em relação ao aumento do rendimento médio da soja no estado, fato muito provavelmente ligado ao aumento da demanda mundial por produtos do complexo soja (em particular, provocada pelo consumo chinês). De 2006 em diante o aumento do rendimento médio voltou a ser maior que o uso de novas áreas para plantio de soja; porém, cabe ressaltar que, a partir de 2007, a evolução do aumento de área plantada segue crescendo de maneira nunca antes vista desde o ano de 1990, o que demonstra que a incorporação de novas áreas (sejam estas antigas áreas de pastagem ou vegetação nativa) mostra uma tendência crescente em Mato Grosso do Sul. 


\section{Gráfico 3. Mato Grosso do Sul. Área plantada de soja (ha) e rendimento médio da produção (kg/ha), 1990-2017.}

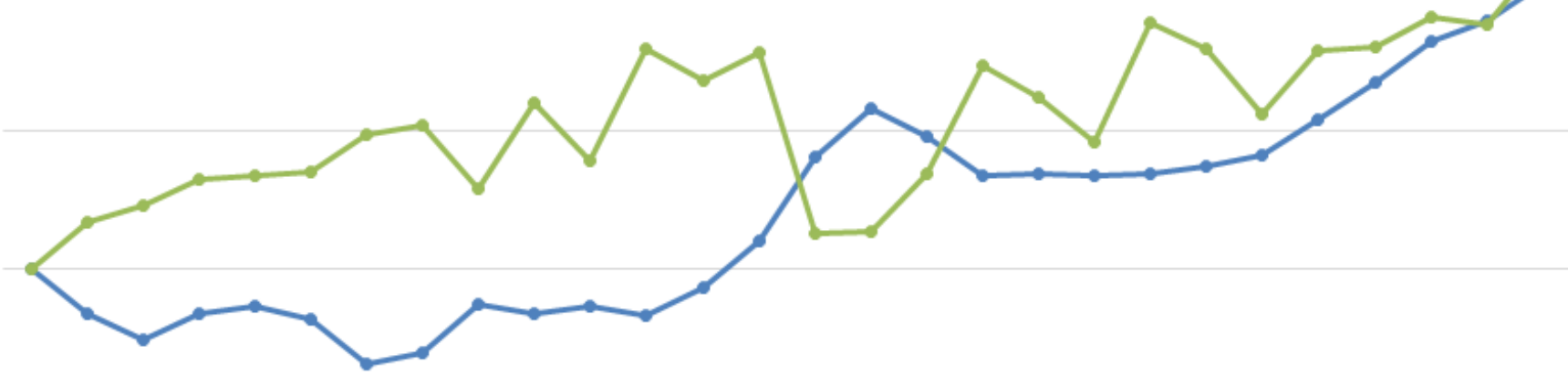

Fonte: Produção agrícola municipal, IBGE (2019).

O mapa 2 demonstra a espacialização dos dados que atestam de forma conclusiva a expansão da área plantada nas últimas décadas no estado. Essa forma predatória de expansão é condizente com a dinâmica da produção moderna; ainda ocorre o avanço das lavouras sobre porções de vegetação nativa, assim como também é aplicado um manejo mais tecnológico das lavouras, aumentando seu rendimento médio por hectare, por meio do uso massivo de fertilizantes e agrotóxicos. É fato que a expansão do cultivo de commodities encontra poucos obstáculos em áreas de fronteira agrícola, o que sugere que o crescente volume produzido de soja no estado se deve mais à expansão horizontal (ocupação de novas áreas) do que à expansão vertical (aumento do rendimento). 
Mapa 2. Mato Grosso do Sul. Evolução da área plantada de soja: 1990, 1995, 2000, 2005, 2010 e 2015.
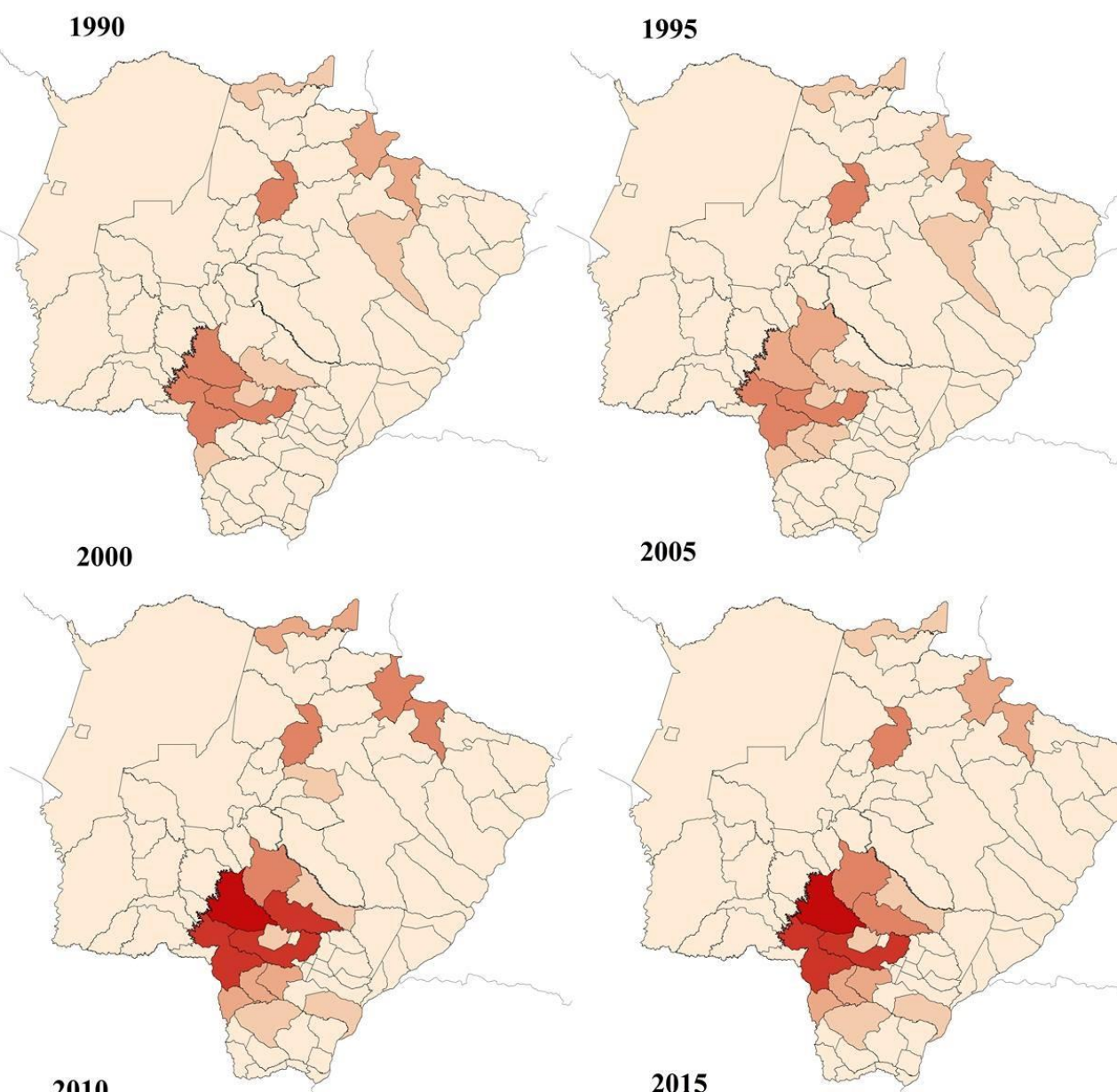

2005
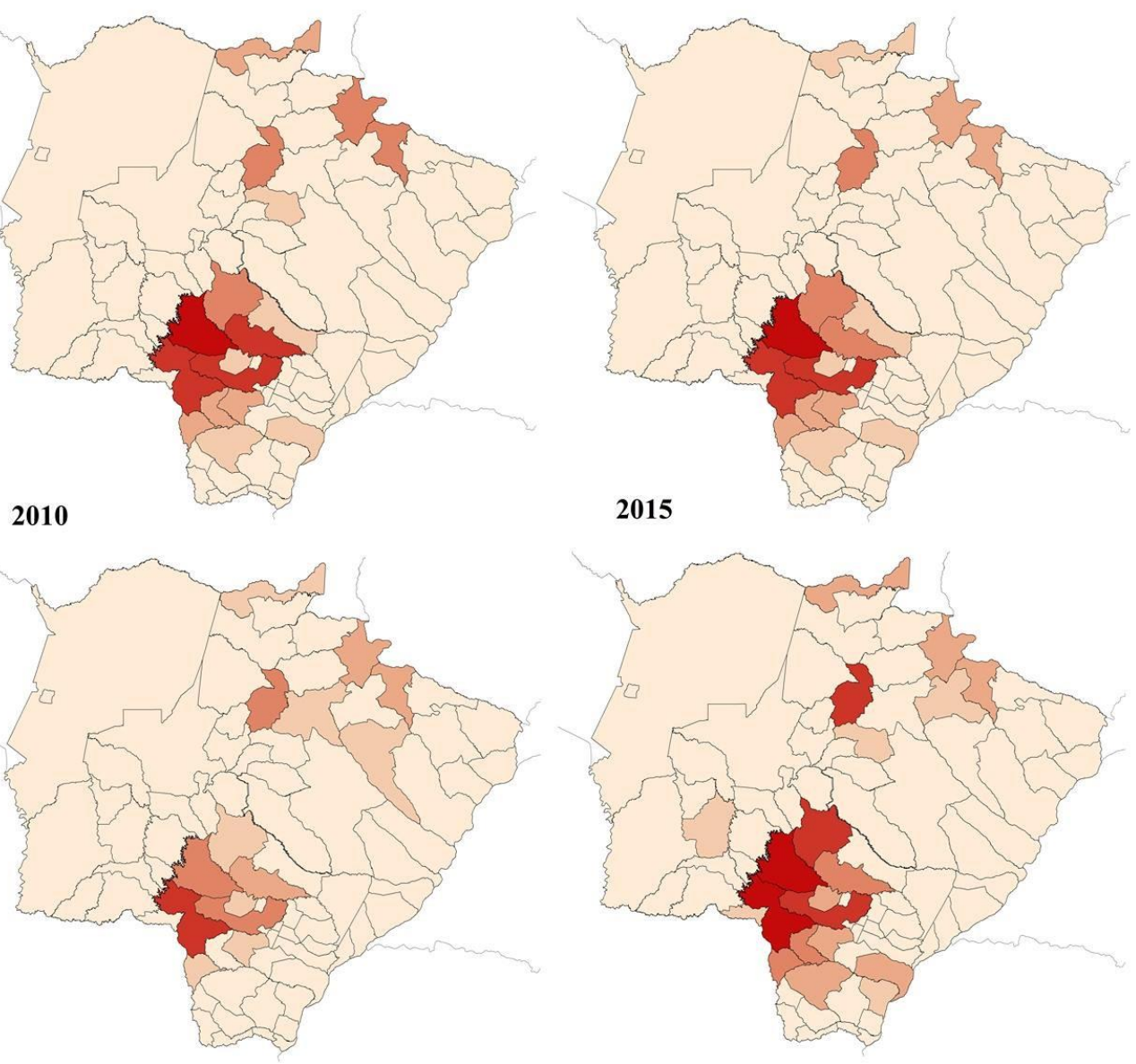

Legenda (hectares)
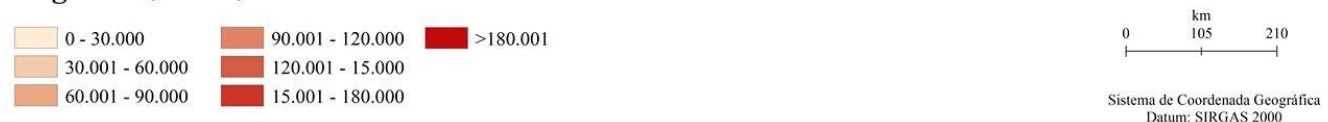

Fonte: Produção agrícola municipal, IBGE (2016), FACCIN (2017). 
Pode-se determinar que a evolução do cultivo da soja em território sul-matogrossense é ditada pela volatilidade dos preços pagos pela soja no mercado internacional. Diante disso, é impossível entender o crescimento da produção sulmato-grossense sem levarmos em conta o período denominado "superciclo de commodities", pois a elevação dos preços gera um impacto direto no espaço dos países periféricos que exportam grandes quantidades de produtos primários ou semimanufaturados.

A evolução dos valores das exportações brasileiras (gráfico 4) demonstra claramente o crescimento da exportação de produtos básicos a partir do ano de 2005 (um ano chave do período, no que se refere aos preços das principais commodities e para a dinâmica da soja em Mato Grosso do Sul). Cabe ressaltar que o gráfico apresenta forte distorção/aumento a partir do ano de 2005 em razão da entrada da China na Organização Mundial do Comércio (OMC).

\section{Gráfico 4. Brasil. Evolução dos índices de valores das exportações totais, segundo a agregação de valor, 1997-2010.}

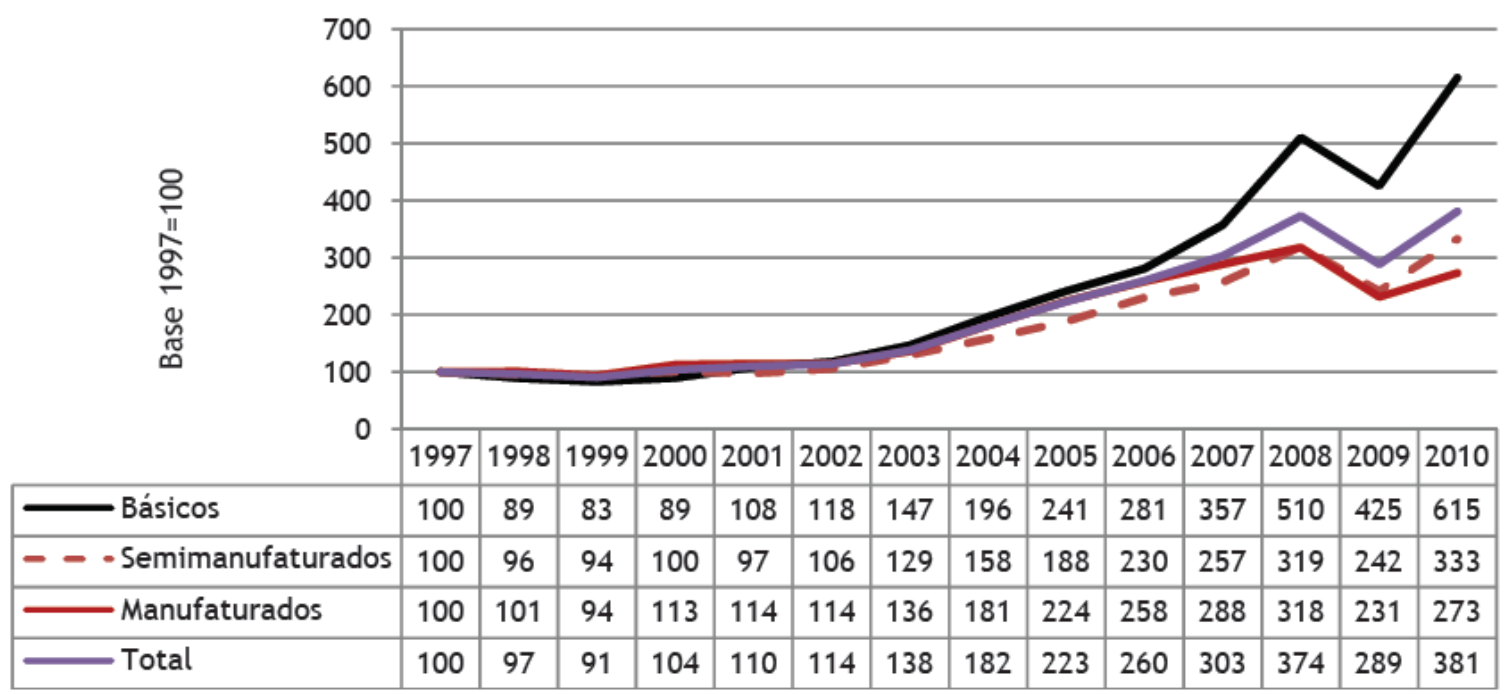

Fonte: GONÇALVES (2011).

O grau de especialização regional produtiva, ou aquilo que já foi chamado de "taxa de monocultura" (SAMPAIO, 2015), é o elemento central da relação entre competitividade e vulnerabilidade territorial, uma vez que as commodities agrícolas se caracterizam, teoricamente, pela permanente oscilação de seu preço em função do jogo entre oferta e demanda, frequentemente perturbada por eventos políticos, na escala mundial. A dedicação maior ou menor de um município (pertencente a uma 
região produtiva especializada) a uma única atividade econômica pode comprometer a economia local de forma profunda futuramente, assim como a pouca diversidade produtiva pode comprometer o abastecimento local no presente.

\section{Considerações Finais}

A expansão da sojicultura no Brasil, particularmente no Cerrado, se deve a uma série de fatores técnicos e políticos, que envolvem desde as inovações biotecnológicas, com a produção de cultivares adaptadas às condições edafoclimáticas desse bioma (e às suas variações), até a inevitável participação do Estado como fomentador e articulador dos agentes privados, tudo em função da demanda externa por commodities. Assim, todo o crescimento do cultivo da soja em Mato Grosso do Sul é modulado pela volatilidade dos preços da soja no mercado globalizado e, no estado, a silvicultura e o setor sucroenergético seguem caminhos semelhantes. Diante disso, é impossível compreender o crescimento da produção sul-mato-grossense e sua dinâmica espacial sem levarmos em conta o período denominado "superciclo de commodities", pois, como destacado neste artigo, a simples elevação dos preços da soja de fato gera um impacto direto no espaço dos países periféricos com economias baseadas na exportação de commodities.

Assim, alertamos que a extrema especialização produtiva causada por esse consumo global dá margem a todo tipo de vulnerabilidade territorial (econômica, social, política e ambiental). Tal fenômeno acomete principalmente cidades profundamente envolvidas com o agronegócio e se dá em razão de acontecimentos externos, cujo controle ultrapassa a escala do lugar e da região. Ainda que o estado de Mato Grosso do Sul não tenha tanto destaque como outros estados intimamente ligados à sojicultura como Mato Grosso, Paraná, acreditamos que, no momento presente, várias regiões sojícolas de Mato Grosso do Sul são extremamente funcionais ao agronegócio e que podem, futuramente, apresentar grande vulnerabilidade territorial.

\section{REFERÊNCIAS}

AB'SABER, A. N. Potencialidades paisagísticas brasileiras. Geomorfologia n. 55. São Paulo, Instituto de Geografia da USP, 1977. 
ASSOCIAÇÃO BRASILEIRA DAS INDÚSTRIAS DE ÓLEOS VEGETAIS - ABIOVE. Estatísticas. Disponível em: $<$ http://www.abiove.org.br/site/index.php?page=estatistica\&area=NCOyLTE $=>$. Acesso em: 05 abr. 2015.

BORRAS JR, SATURNINO M.; FRANCO, J C.; ISAKSON, R; LEVIDOW, L and VERVEST, P. Towards Understanding the Politics of Flex Crops and Commodities: Implications for Research and Policy Advocacy. Think Piece Series on Flex Crops \& Commodities. Amsterdam: Transnational Institute, 2014.

BRASIL. Ministério da Indústria, Comércio Exterior e Serviços. Alice Web. Disponível em: < http://aliceweb.mdic.gov.br/>. Acesso em: 20 jan. 2017.

BRASIL. Portal Siscomex. Secretaria de comércio exterior, SECEX. Disponível em: < http://portal.siscomex.gov.br/legislacao/orgaos/secretaria-de-comercio-exterior-secex>. Acesso em 10 jan. 2017.

CASTILLO, R. Expansão recente do setor sucroenergético no território brasileiro: algumas implicações nas escalas local, regional e nacional.55 Congreso Internacional de Americanistas. San Salvador, 2015.

CASTILLO, R. Agronegócio e Logística em Áreas de Cerrado: expressão da agricultura científica globalizada. Revista da ANPEGE. v. 3, p. 33 - 43, 2007.

CASTILLO, R. Expansão recente do setor sucroenergético no território brasileiro: algumas implicações nas escalas local, regional e nacional. Association of American Geographers, Annual Meeting, Chicago, 2015.

CANO, W. Desconcentração produtiva regional do Brasil: 1970-2005. São Paulo: UNESP, 2008.

COMEX VIS - Visualizações de Comércio Exterior. Ministério da Economia, Indústria, Comércio Exterior e Serviços. Disponível em :< http://www.mdic.gov.br/comercioexterior/estatisticas-de-comercio-exterior/comex-vis>. Acesso em: 08 jan 2019.

DELGADO, G. Mudança técnica na agricultura, constituição do complexo agroindustrial e política tecnológica recente. Cadernos de Ciência e Tecnologia, 21, 1, p. 79-97, 1985

DIAS, L. C. Redes: emergência e organização. In: CASTRO, I. E. et al. (Org.). Geografia: conceitos e temas. Rio de Janeiro: Bertrand Brasil, 1995.

DIAS, L. C. Os sentidos da rede: notas para discussão. In: DIAS, L. C. \& SILVEIRA, R. L. L. (org.). Redes, sociedades e territórios. Santa Cruz do Sul: EDUNISC, 2005.

DINIZ, B. C. O grande cerrado do Brasil Central: geopolítica e economia. Tese (Doutorado em Geografia Humana). Faculdade de Filosofia, Letras e Ciências Humanas da Universidade de São Paulo. São Paulo, 2006.

ELIAS, D. O meio técnico-científico-informacional e a reorganização do espaço agrário nacional. In: MARAFON, G. J; RUA, J.; RIBEIRO, M. A. (Orgs.). Abordagens teóricometodológicas em geografia agrária. P. 49-66.1 ed. RJ: Ed UERJ, 2007.

EMBRAPA - EMPRESA BRASILEIRA DE PESQUISA AGROPECUÁRIA. Comunicado técnico. Sucessão soja/soja safrinha em Mato Grosso do Sul: um modelo de produção com sustentação agronômica? Dourados, 2015. Disponível em: < https://www.infoteca.cnptia.embrapa.br/infoteca/bitstream/doc/1031726/1/COT2015206COR RIGIDO.pdf>. Acesso em: 05 jun. 2016. 
EMBRAPA - EMPRESA BRASILEIRA DE PESQUISA AGROPECUÁRIA. Software Embrapa Soja. Disponível em: <https://www.embrapa.br/soja>. Acesso em: 10 fev. 2015.

FACCIN, A. C. T. M. Complexo soja no Mato Grosso do Sul: competitividade regional e vulnerabilidade territorial. Tese (Doutorado em Geografia). Faculdade de Ciências Humanas, Universidade Federal da Grande Dourados. Dourados, 2017.

GONÇALVES, J. S. Reprimarização ou Desindustrialização da Economia Brasileira: uma leitura a partir das exportações para o período 1997-2010. Análises e Indicadores do Agronegócio, v. 6, n. 12, 2011.

GUIMARÃES, E. N; LEME, H. J. C. Caracterização histórica e configuração espacial da estrutura produtiva do Centro-Oeste. In: HOGAN, Daniel Joseph (Org.). Migração e ambiente no centro-oeste. P. 17-74. Campinas: PRONEX, 2002.

HARVEY, D. O novo imperialismo. São Paulo: Loyola, 2004

INSTITUTO BRASILEIRO DE GEOGRAFIA E ESTATÍSTICA - IBGE. Produção Agrícola Municipal. Disponível em:

<http://www.ibge.gov.br/home/estatistica/pesquisas/pesquisa_resultados.php?id_pesquisa=4 4>. Diversas consultas. Acesso em: 20 dez. 2016.

LAMOSO, L. P. Dinâmicas Produtivas da Economia de Exportação no Mato Grosso do Sul Brasil. Mercator, Fortaleza, v. 10, n. 21, p.33-47, jan. /abr. 2011.

OLIVEIRA, J. Análise do Transporte de Soja, Milho e Farelo de Soja na Hidrovia TietêParaná. Dissertação de mestrado. Escola Superior de Agricultura Luiz de Queiroz, 1996.

OLIVEIRA, T. C. M. de. Agroindústria e reprodução do espaço. Campo Grande, MS: UFMS, 2003. 260 p.

SAMPAIO, M. A. P. 360ㅇ: périplo do açúcar em direção à Macrorregião Canavieira do Centro-Sul do Brasil. Tese (Doutorado em Geografia Humana). Faculdade de Filosofia, Letras e Ciências Humanas da Universidade de São Paulo. São Paulo, 2015

SANTOS, M. A natureza do espaço. Técnica e tempo, razão e emoção. São Paulo: Hucitec, 1994.

SANTOS, M. Metamorfoses do espaço habitado. São Paulo: Hucitec, 1989.

SOUZA, A. O. Modernização e desenvolvimento: aspectos da política hidroviária no Mato Grosso do Sul. In: LAMOSO, L (Org.). Transportes e políticas públicas em Mato Grosso do Sul. P. 117-134. Dourados: Editora da UFGD, 2008.

SOUZA, A. O. Mato Grosso do Sul no contexto dos novos paradigmas de integração e desenvolvimento nacional. Dourados, MS: Editora da UFGD, 2008.

WENTZEL, M. Brasil passa por desindustrialização precoce, aponta pesquisa da ONU. BBC Brasil. Disponível em: < http://www.bbc.com/portuguese/brasil-37432485>. Acesso em: 10 jan. 2017. 


\section{NOTAS DE AUTOR}

\section{CONTRIBUIÇÃO DE AUTORIA}

Ana Carolina Torelli Marquezini Faccin - Concepção. Coleta de dados, Análise de dados, Elaboração do manuscrito, revisão e aprovação da versão final do trabalho

Ricardo Castillo - Orientação, colaboração e correção do manuscrito. Participação ativa da discussão dos resultados; Revisão e aprovação da versão final do trabalho.

\section{FINANCIAMENTO}

Bolsa de pesquisa CAPES-DS (cota PPGG/FCH/UFGD). Bolsa de pesquisa CAPES-COFECUB (processo n8824/14-2, missão de estudos no exterior).

\section{CONSENTIMENTO DE USO DE IMAGEM}

Não se aplica

\section{APROVAÇÃO DE COMITÊ DE ÉTICA EM PESQUISA}

Não se aplica

\section{CONFLITO DE INTERESSES}

Não se aplica.

\section{LICENÇA DE USO}

Este artigo está licenciado sob a Licença Creative Commons CC-BY. Com essa licença você pode compartilhar, adaptar, criar para qualquer fim, desde que atribua a autoria da obra.

\section{HISTÓRICO}

Recebido em: 01-02-2019

Aprovado em: 03-03-2019 